\title{
Sampling of exhaled nitric oxide in children: end-expiratory plateau, balloon and tidal breathing methods compared
}

\author{
Q. Jöbsis*, S.L. Schellekens*, A. Kroesbergen*, W.C.J. Hop**, J.C. de Jongste*
}

\begin{abstract}
Sampling of exhaled nitric oxide in children: end-expiratory plateau, balloon and tidal breathing methods compared. Q. Jöbsis, S.L. Schellekens, A. Kroesbergen, W.C.J. Hop, J.C. de Jongste. (C) ERS Journals Ltd 1999.

ABSTRACT: The aim of this study was to compare exhaled nitric oxide concentrations obtained during controlled slow exhalation, presently considered as the method of choice, with two sampling methods that are easily performed by children: blowing air into a balloon and tidal breathing through a mouthpiece.

One hundred and one well controlled, stable allergic asthmatic children (median age $11.7 \mathrm{yrs}$ ) performed the following tasks in duplicate: 1) exhalation from total lung capacity through a mouthpiece against a resistor with a standardized flow rate of $20 \%$ of the subject's vital capacity per second, using a biofeedback system; 2) a single deep exhalation into an NO-impermeable mylar balloon; and 3) tidal breathing through a low resistance mouthpiece over 2 min. NO was measured using a chemiluminescence analyser.

Twenty-nine children (29\%) were not able to perform a constant-flow exhalation of at least 3 s. All children performed the balloon and tidal breathing methods without difficulty. NO concentrations (means \pm SEM) were $5.3 \pm 0.2$ parts per billion (ppb) at the end-expiratory plateau, $5.2 \pm 0.3 \mathrm{ppb}$ in balloons (intraclass correlation coefficient $\left.\left(r_{i}\right)=0.73\right)$ and $8.0 \pm 0.4$ ppb during tidal breathing $\left(p<0.001, r_{i}=0.53\right.$ compared to plateau values). Mean values of NO during tidal breathing increased significantly with time, suggesting increasing contamination with nasal air.

It was concluded that, in asthmatic children, the end-expiratory plateau concentration of nitric oxide during exhalation at $20 \%$ of the vital capacity per second is similar to the values obtained with the balloon method, with satisfactory agreement, but differs from values obtained during tidal breathing. The balloon method is cheap, simple and offers the interesting possibility to study exhaled nitric oxide in young children independently of the presence of a nitric oxide analyser.

Eur Respir J 1999; 13: 1406-1410.
\end{abstract}

\begin{abstract}
*Dept of Paediatrics, Division of Paediatric Respiratory Medicine and **Dept of Biostatistics, Erasmus University Medical Centre/Sophia Children's Hospital,
\end{abstract} Rotterdam, the Netherlands.

Correspondence: J.C. de Jongste Sophia Children's Hospital, room Sp-2465

Dr Molewaterplein 60

3015 GJ Rotterdam

The Netherlands

Fax: 31104636801

Keywords: Asthma

balloon method

children

exhaled air

nitric oxide

tidal breathing

Received: April 231998

Accepted after revision December 71998
Invasive procedures such as bronchoscopy and bronchoalveolar lavage (BAL) have greatly enhanced the understanding of the role of inflammation in asthma [1-3]. In young children, BAL is generally not acceptable for research, diagnosis and monitoring purposes. A noninvasive method to assess the presence and severity of airway inflammation is important for this group [4]. GUSTAFSSON et al. [5] demonstrated that nitric oxide can be detected in the exhaled air of animals and humans. NO is produced by various cells within the respiratory tract, and plays an important role in the pathophysiology of inflammatory airway disease $[6,7]$.

In recent years, the measurement of NO in exhaled air has been studied for its potential as a marker of airway inflammation in both diagnosis and management. Increased amounts of NO have been detected in the exhaled air in humans with various inflammatory airway disorders [8-12]. There is persuasive evidence that levels of NO are decreased by anti-inflammatory therapy [13-16]. However, different groups have reported widely varying levels of exhaled NO in similar patient groups and in healthy subjects, probably owing to differences in methodology $[17,18]$.
In an attempt to standardize NO measurement in exhaled air, a European Respiratory Society (ERS) task force report was recently published [18]. In adults and children (from the age of 6 yrs), a slow exhalation from total lung capacity (TLC) through a mouthpiece with a constant flow against a resistance was recommended for the measurement of NO in exhaled air. It appears, however, that children may have difficulty maintaining a fixed flow. As recommended in the ERS task force report, a balloon method, a simple technique which is easily performed by children, was used in this study to measure exhaled NO. Others have proposed a tidal breathing method with measurement of NO in the mixed expired air during resting ventilation, with or without a fixed resistor in the expiration circuit $[8,19,20]$. Comparison between these different sampling methods in subjects is needed.

The aim of this study was to compare in subjects: 1) single exhalation from TLC with a constant flow against a resistance; 2) single uncontrolled deep expiration into a balloon; and 3) continous sampling of exhaled air during tidal breathing without expiratory resistance. Furthermore, the short term reproducibility of NO measurements in exhaled air with the different sampling methods was assessed. 


\section{Patients and Methods}

\section{Study population}

One hundred and one stable asthmatic children (67 males and 34 females) attending the outpatient clinic for paediatric respiratory medicine at Sophia Children's Hospital were included. Their median age was 11.7 yrs (range 7.0-17.6 yrs). Asthma was diagnosed on clinical grounds and according to international guidelines [21]. All had bronchial hyperresponsiveness (a provocative dose of inhaled methacholine that produced a $20 \%$ fall in forced expiratory volume in one second (PD20) of $<150 \mu \mathrm{g}$ ) documented in the past, and had allergy as documented by a radioallergosorbent test (RAST) class 2 or higher for at least one common airborne allergen. Appropriate therapy was prescribed by the patient's own physician, and had not been changed during the 3 months preceding the study. All subjects used an inhaled bronchodilator on demand, 90 (89\%, 60 males and 30 females) used an inhaled corticosteroid (mean dose $400 \mu \mathrm{g} \cdot$ day $^{-1}$ budesonide or beclomethasone, range $100-1,500 \mu \mathrm{g} \cdot$ day $^{-1}$ ), and 23 used long-acting $\beta$-agonists. All were lifelong nonsmokers and were clinically stable. None of the subjects reported symptoms of acute respiratory infection within the month before NO was measured. The study was approved by the medical ethics committee of the university hospital.

\section{Lung function}

All subjects underwent flow-volume measurements immediately before NO was measured. Flow-volume curves were obtained in triplicate, using a Lilly-type pneumotachograph (Masterlab Jaeger, Würzberg, Germany). Results of forced expiratory volume in one second (FEV1) and forced (expiratory) vital capacity (FVC) were expressed as percentage predicted [22].

\section{Exhaled air sampling and nitric oxide measurement}

All subjects performed three different expiratory manoeuvres in duplicate, always in the same order.

A single slow exhalation. Children were instructed to perform a slow exhalation from TLC through a mouthpiece and a two way nonrebreathing valve (Rudolph Inc., Kansas City, MO, USA) into a wide bore teflon tube against an inline resistor $\left(20 \mathrm{cmH}_{2} \mathrm{O} \cdot \mathrm{L}^{-1} \cdot \mathrm{s}\right.$, Rudolph Inc.) with an individually standardized flow rate of $20 \%$ of the subject's vital capacity (VC) per second. A biofeedback exhalation flow display provided visual guidance to help the subject maintain their exhalation flow at the desired level. The mean end-expiratory NO level was measured in duplicate from air sampled from exhalation at $200 \mathrm{~mL} \cdot \mathrm{min}^{-1}$ via teflon tubing during an end-expiratory flow plateau of at least $3 \mathrm{~s}$.

One single deep expiration into a balloon. Subjects were asked to take a deep breath, not necessarily to TLC, and to perform one single deep exhalation via a plastic tube (length $5 \mathrm{~cm}, 3.7 \mathrm{~mm}$ i.d.) into an $\mathrm{NO}$ impermeable mylar balloon (maximum capacity $1,750 \mathrm{~mL}$ ). Flow and pressure were not monitored, but with the balloon filling in 3-5 $\mathrm{s}$, to a volume of $1,250-1,750 \mathrm{~mL}$, flow rates would range $250-600 \mathrm{~mL} \cdot \mathrm{s}^{-1}$. Preliminary measurements showed that, during balloon blowing, oral positive pressure was always $>6 \mathrm{cmH}_{2} \mathrm{O}$, sufficient to close the velum and prevent nasal contamination of exhaled air. Gas was sampled from the balloon within $15 \mathrm{~min}$ after filling. The mean NO concentration was measured during $30 \mathrm{~s}$ of sampling from the balloon (at $200 \mathrm{~mL} \cdot \mathrm{min}^{-1}$ ). This manoeuvre was performed in duplicate.

Tidal breathing. Subjects performed 2 min of quiet tidal breathing through a mouthpiece connected to a two-way nonrebreathing valve into a wide bore low resistance teflon tube, where gas was continuously sampled via a side port at $200 \mathrm{~mL} \cdot \mathrm{min}^{-1}$. The mean $\mathrm{NO}$ value of the first minute and of the second minute were calculated by computer.

All measurements were performed with the children seated. All children were allowed 2 min rest between the different expiratory manoeuvres to restore resting conditions of ventilation. They did not wear a noseclip. To exclude the effect of high ambient NO levels on the level of exhaled NO, all tests were performed with ambient NO concentrations $<10$ parts per billion (ppb). Preliminary experiments demonstrated that $\mathrm{NO}$ concentrations in mylar balloons remained stable for at least $6 \mathrm{~h}$. NO was measured with a chemiluminescence analyser (Sievers 280, Boulder, CO, USA) with a sampling flow rate of $200 \mathrm{~mL} \cdot \mathrm{min}^{-1}$ and a response time of $200 \mathrm{~ms}$. The analyser was regularly calibrated according to the manufacturer's guidelines, using certified NO gases (100 ppb and 9 ppm) and certified NO-free gas (HoekLoos, Barendrecht, the Netherlands).

\section{Data analysis}

Data of NO concentration and flow rates were entered into a computer at a sampling rate of $20 \mathrm{~Hz}$. Mean values of NO concentrations at selected time intervals were calculated afterwards by means of a custom data processing program. Data are presented as mean \pm SEM. End-expiratory NO during exhalation from TLC with a continuous flow was taken as the gold standard. The agreement of the balloon method and the tidal breathing method with endexpiratory levels was assessed according to BLAND and Altman [23]. As these plots indicated that the outcome variability increased with increasing NO levels, further analysis was carried out using logarithmically transformed data. Mean data from the different methods were compared using the Student t-test for paired samples. To characterize the agreement between methods, intraclass correlation coefficients $\left(r_{i}\right)$ were calculated [24]. The same methods were used to analyse within-subject reproducibilities. A two tailed p-value $<0.05$ was considered as significant.

\section{Results}

Lung function measurements showed near-normal mean values (mean \pm SEM): FVC $103 \pm 2 \%$ predicted, FEV $194 \pm 2 \%$ pred. Twenty-nine children (29\%) (mean age $11.0 \mathrm{yrs}$, 
range 7.3-16.3 yrs) were not able to sustain a stable end expiratory flow plateau of at least $3 \mathrm{~s}$. In contrast, all children performed the balloon method and the tidal breathing method without any difficulty. In the 72 stable asthmatic children (mean age $12.1 \mathrm{yrs}$, range 7-17.6 yrs) who performed the three different procedures successfully, NO concentrations (median (range)) were $5.0(2.3-12.8) \mathrm{ppb}$ at the end expiratory plateau; 4.8 (2.2-17.2) ppb from balloons; and $7.8(2.7-20.0) \mathrm{ppb}$ during tidal breathing ( $\mathrm{p}=0.43$ and $\mathrm{p}<0.001$, respectively, compared to plateau values).

The within-method short-term reproducibility of duplicate NO values obtained at the end-expiratory plateau and from balloons was excellent $\left(r_{i}=0.90\right.$ and 0.91 , respectively). The reproducibility of the tidal breathing method was less $\left(r_{i}=0.85\right)$. With tidal breathing, consistently higher mean NO concentrations were found during the second minute than during the first minute $(8.5 \mathrm{ppb}$ versus 7.5 $\mathrm{ppb}$ ), the difference being dependent on mean NO concentration. The mean of all individual coefficients of variation of all NO values was $7 \%$ for the end-expiratory plateau, $7 \%$ for the balloon method, and $22 \%$ for the tidal breathing method. Ninety per cent of all within-subject coefficients of variation were $<15 \%$ for the end-expiratory plateau, $<12 \%$ for the balloon method, and $<81 \%$ for tidal breathing.

Comparison of the average NO (duplicate measurements) obtained at the end-expiratory plateau and from balloons showed a statisfactory agreement between the two sampling methods $\left(\mathrm{r}_{\mathrm{i}}=0.73\right.$ ) (fig. 1$)$, and this was similar if the first NO measurements only were considered $\left(r_{i}=\right.$ 0.72 ). The geometric mean ratio of $\mathrm{NO}$ values obtained at the end-expiratory plateau and with the balloon was 1.05 ppb with 2.5 and 97.5 percentiles of 0.60 and $1.60 \mathrm{ppb}$, respectively (fig. 2), indicating no systematic error and good agreement. In contrast, a poor agreement was found between the NO values obtained with the tidal breathing method and at the end expiratory plateau, with $\mathrm{r}_{\mathrm{i}}=0.52$ for duplicate measurements, and $\mathrm{r}_{\mathrm{i}}=0.53$ for single measurements (fig. 3).

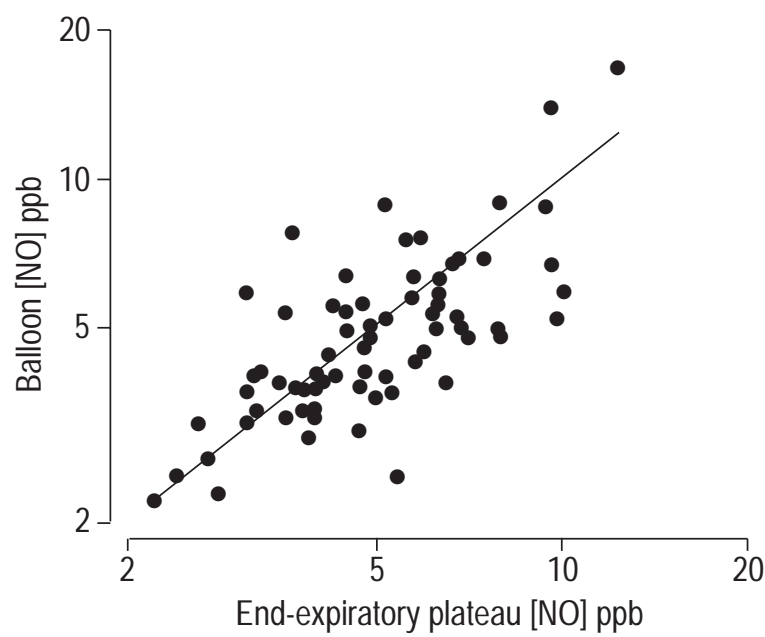

Fig. 1. - Comparison of exhaled nitric oxide concentrations obtained during a single exhalation at a fixed flow of $20 \%$ of vital capacity per second and values measured in mylar balloons filled with a single deep exhalation. Data are from 72/101 children who were capable of performing both methods. there is good agreement with an $r_{i}$ of 0.73 . The line represents line of identity. Note the logarithmic scale.

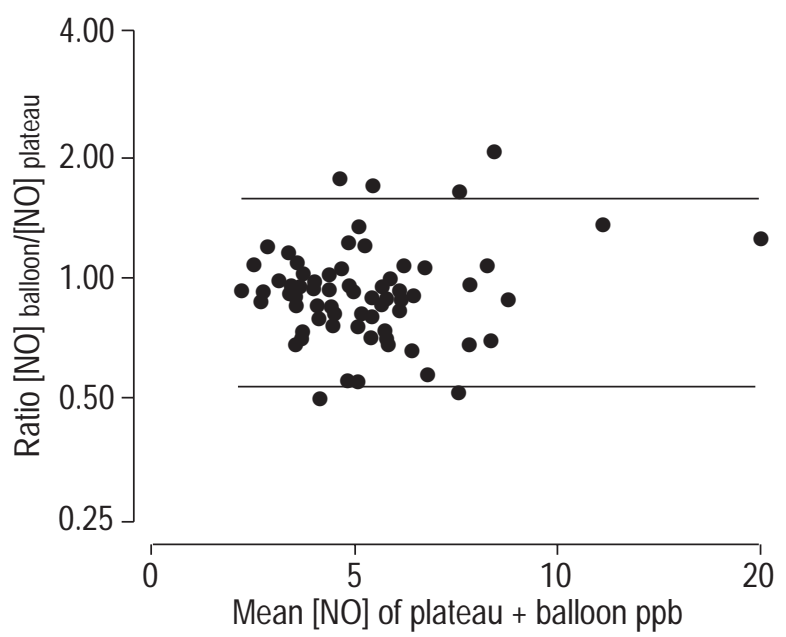

Fig. 2. - Ratios of exhaled nitric oxide concentrations obtained from mylar balloons and at an end-expiratory plateau during exhalation with constant flow of $20 \%$ of vital capacity per second (logarithmic scale), plotted against their means. The average ratio is 1.05; horizontal lines indicate the 2.5-97.5 percentile range. A good agreement was noted with no systematic error. ppb: parts per billion.

\section{Discussion}

This is the first study in children that has compared different sampling methods for exhaled NO. Thirty per cent of the children studied were not able to perform the recommended sampling procedure of single slow exhalation with a constant flow against a resistance. This underlines the importance of developing alternative methods for use in children. Until recently, measurement techniques for expired NO were not standardized. Values have been obtained for peak expired NO, end-expiratory plateau levels, mixed expired levels during tidal breathing and NO production over time. This study compared three different NO measurement methods in stable asthmatic children, using controlled exhalation with constant flow as a gold

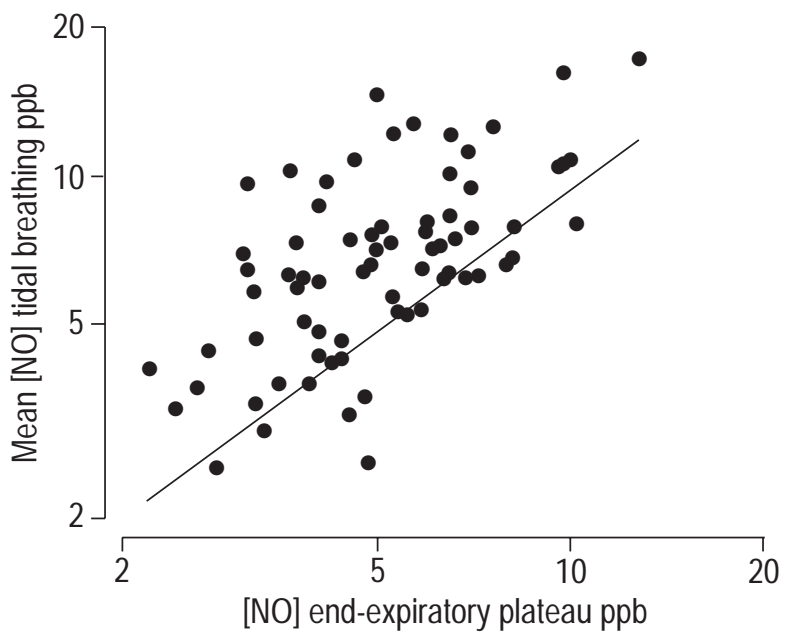

Fig. 3. - Comparison of exhaled nitric oxide concentrations obained at the end-expiratory plateau during a single exhalation at a fixed flow of $20 \%$ of vital capacity per second and the mean concentration of exhaled NO during 2 min of quiet tidal breathing. Data are from 72/101 children who could perform both methods satisfactorily. There is poor agreement with an $r_{i}=0.52$; NO values during tidal breathing showed an increase over time. Note the logarithmic scale. ppb: parts per billion. 
standard. Satisfactory agreement and no significant differences were found between the end-expiratory plateau value of NO during exhalation at $20 \%$ of VC per second and NO values obtained from a balloon. However, there was a highly significant time and concentration-dependent difference between NO values during tidal breathing and at the end-expiratory plateau, suggesting that sampling during tidal breathing without expiratory resistance has limited value in children.

Relatively low NO values were found in well controlled asthmatic children, most of whom used inhaled steroids. This is in agreement with a number of other studies showing that inhaled steroids normalize exhaled $\mathrm{NO}$ in asthmatics [11, 13, 15].

Regarding the feasibility of slow exhalation with constant flow, the present results are different from those of BALFOUR-LyNN et al. [25], who reported single slow exhalations against a resistance by 63 children with cystic fibrosis and 57 normal children aged 6-17 yrs. However, they did not control for the exhalation flow rate or pressure. As the concentration of NO depends on air flow $[26,27]$, maintaining a constant expiratory flow is now considered important [18].

Other studies have measured NO in mixed exhaled air, collected in a reservoir during tidal breathing $[19,20]$. In the present study, mean exhaled NO values obtained with the tidal breathing method were significantly higher than those obtained with the other two methods and increased with time. This could well be due to contamination from nasal NO. During tidal breathing, NO may diffuse from the upper airways and contaminate orally exhaled air, as the soft palate opens during inspiration $[26,28]$. Although contamination of orally exhaled NO by nasal NO can be prevented by single exhalations against a resistance $[26$, 29], an expiratory resistor was not used during tidal breathing. The palate will open during tidal inspiration regardless, thereby allowing for contamination with nasal NO.

No significant differences, and a good agreement were found between the concentration of NO in balloons and during controlled single exhalations. Balloon filling through the resistor tube produced at least $6 \mathrm{cmH}_{2} \mathrm{O}$ positive pressure in the mouth, which will close the soft palate. This has been previously demonstrated in studies using argon gas, a tracer applied to the nose that was not retrieved in either the exhaled air or in balloons [30, 31].

The balloon method collects air not only from the alveolar compartment, but also from the dead space. The potential effect of the dead space on the NO concentration in the balloon is a point of concern, as the concentration of NO in the dead space may be relatively high, causing an initial NO peak during slow exhalations. However, no systematic difference was found between the balloon method and single exhalations with constant flow. This may partly be explained by the fact that children have a smaller dead space than adults which, with a similar balloon volume, will have a smaller effect on mixed NO values. To prevent accumulation of NO in the airways and nasal NO entering the dead space compartment, care was taken that the NO in the ambient air was kept $<10 \mathrm{ppb}$, that children inhaled through the mouth, and exhaled immediately without breath holding. Another point of concern in the balloon method is the lack of flow standardization. However, the short-term reproducibility of NO data obtained with the balloon method appeared excellent, and corresponded well with end-expiratory plateau NO levels during exhalation at a constant flow. This may be explained by the relatively high flow rate used in both methods; it is evident that flow dependency is most important with very low flow rates of approximately $\leq 200$ $\mathrm{mL} \cdot \mathrm{min}^{-1}$ [26], whereas dependency is much less at higher flow rates such as that employed in the present study. It may be advantageous to adapt the balloon method for lower, controlled flow rates, although this would require a more complicated system and better cooperation and skills from the children [31, 32].

Recently, Deykin et al. [33] demonstrated that repeated spirometry may induce a slow onset, prolonged fall in exhaled NO. In the present study spirometry was performed immediately before NO sampling and may have introduced a bias. However, all measurements were always performed in the same order, mostly within 15 min, whereas the maximal fall in NO after spirometry reported by DEYKIN et al. [33] occurred after $30 \mathrm{~min}$; furthermore, an excellent within-method short-term reproducibility of single exhalations and balloons, without a downward trend, was found in the present study. Therefore, it is believed that the possible systematic error induced by the spirometry does not invalidate the results from this study.

In conclusion, a simple and reproducible method of measuring exhaled nitric oxide in balloons was described, producing results that are similar to the values obtained at an end-expiratory plateau. The balloon method is feasible in young children and has the additional advantage that it can be carried out independent of the presence of a nitric oxide analyser.

\section{References}

1. Smith DL, Deshazo RD. Bronchoalveolar lavage in asthma: an update and perspective. Am J Respir Crit Care Med 1993; 148: 523-532.

2. Grigg J, Venge P. Inflammatory markers of outcome. Eur Respir J 1996; 9: Suppl. 21, 16s-21s.

3. Holgate ST. The immunopharmacology of mild asthma. $J$ Allergy Clin Immunol 1996; 98: s8-s16.

4. O'Byrne PM, Hargreave FE. Noninvasive monitoring of airway inflammation. Am J Respir Crit Care Med 1994; 150: s100-s102.

5. Gustafsson LE, Leone AM, Persson MG, Wiklund NP, Moncada S. Endogenous nitric oxide is present in the exhaled air of rabbits, guinea-pigs and humans. Biochem Biophys Res Commun 1991; 181: 852-857.

6. Barnes PJ, Belvisi MG. Nitric oxide and lung disease. Thorax 1993; 48: 1034-1043.

7. Gaston B, Drazen JM, Loscalzo J, Stamler JS. The biology of nitrogen oxides in the airways. Am J Respir Crit Care Med 1994; 149: 538-551.

8. Alving K, Weitzberg E, Lundberg JM. Increased amount of nitric oxide in exhaled air of asthmatics. Eur Respir $J$ 1993; 6: 1368-1370.

9. Borland C, Cox Y, Higenbottam T. Measurement of exhaled nitric oxide in man. Thorax 1993; 48: 1160-1162.

10. Persson MG, Zetterström O, Argrenius V, Ihre E, Gustafsson LE. Single-breath nitric oxide measurements in asthmatic patients and smokers. Lancet 1994; 343: 146147. 
11. Kharitonov SA, Yates DH, Robbins RA, Logan-Sinclair $\mathrm{R}$, Shinebourne EA, Barnes PJ. Increased nitric oxide in exhaled air of asthmatic patients. Lancet 1994; 343: 133135.

12. Kharitonov SA, Wells AU, O'Conner BJ, et al. Elevated levels of exhaled nitric oxide in bronchiectasis. Am J Respir Crit Care Med 1995; 151: 1889-1893.

13. Lundberg JON, Nordvall SL, Weitzberg E, Kollberg H, Alving K. Exhaled nitric oxide in paediatric asthma and cystic fibrosis. Arch Dis Child 1996; 75: 323-326.

14. Kharitonov SA, Yates DH, Barnes PJ. Inhaled glucocorticosteroids decrease nitric oxide in exhaled air of asthmatic patients. Am J Respir Crit Care Med 1996; 153: 454-457.

15. Massaro AF, Gaston B, Kita D, Fanta C, Stamler JS, Drazen FM. Expired nitric oxide levels during treatment of acute asthma. Am J Respir Crit Care Med 1995; 152: 800-803.

16. Kharitonov SA, Yates DH, Chung KF, Barnes PJ. Changes in the dose of inhaled steroid affect exhaled nitric oxide levels in asthmatic patients. Eur Respir J 1996; 9: 196-201.

17. Lundberg JON, Lundberg JM, Alving K, Weitzberg E. Nitric oxide and inflammation: the answer is blowing in the wind. Nat Med 1997; 3: 30-31.

18. Kharitonov SA, Alving K, Barnes PJ. Exhaled and nasal nitric oxide measurements: recommendations. ERS task force report. Eur Respir J 1997; 10: 1683-1693.

19. Visser MJ, de Wit MY, van Aalderen WMC, Postma DS, Brand PLP. Exhaled nitric oxide in children: significant differences between asthmatics and controls using a method not requiring active patient cooperation. Eur Respir J 1997; 10: 277s.

20. Baraldi E, Azzolin NM, Zanconato S, Dario C, Zacchello F. Corticosteroids decrease exhaled nitric oxide in children with acute asthma. J Pediatr 1997; 131: 381385.

21. Warner JO, Götz M, Landau LI, et al. Management of asthma: a consensus statement. Arch Dis Child 1989; 64: $1065-1079$.
22. Zapletal A, Samanek M, Paul T. Lung Function in Children and Adolescents: Methods, Reference Values. Basel, Krager Verlag, 1987; pp. 191-197.

23. Bland JM, Altman DG. Statistical methods for assessing agreement between two methods of clinical measurement. Lancet 1986; 1: 307-310.

24. Fleiss IL. The Design and Analysis of Clinical Experiments. New York, John Wiley \& Sons, 1986.

25. Balfour-Lynn IM, Laverty A, Dinwiddie R. Reduced upper airway nitric oxide in cystic fibrosis. Arch Dis Child 1996; 75: 319-322.

26. Silkoff PF, McClean PA, Slutsky AS, et al. Marked flowdependence of exhaled nitric oxide using a new technique to exclude nasal nitric oxide. Am J Respir Crit Care Med 1997; 155: 260-267.

27. Lundberg JON, Weitzberg E, Lundberg JM, Alving K. Nitric oxide in exhaled air. Eur Respir J 1996; 9: 26712680.

28. Jöbsis Q, de Jongste JC. Comparison of three different sampling methods of exhaled nitric oxide in children. Am J Respir Crit Care Med 1997; 155: A970.

29. Kharitonov SA, Chung KF, Evans DJ, O'Conner BJ, Barnes PJ. Increased exhaled nitric oxide in asthma is mainly derived from the lower respiratory tract. $\mathrm{Am} \mathrm{J}$ Respir Crit Care Med 1996; 153: 1773-1780.

30. Kharitonov SA, Barnes PJ. Nasal contribution to exhaled nitric oxide during exhalation against resistance or during breath holding. Thorax 1997; 52: 540-544.

31. Paredi P, Loukides S, Ward S, et al. Exhalation flow and pressure-controlled reservoir collection of exhaled nitric oxide for remote and delayed analysis. Thorax 1998; 53: 775-779.

32. Kimberly B, Nejadnik B, Giraud GD, Holden WE. Nasal contribution to exhaled nitric oxide at rest and during breathholding in humans. Am J Respir Crit Care Med 1996; 153: 829-836.

33. Deykin A, Halpern O, Massaro AF. Expired nitric oxide after bronchoprovocation and repeated spirometry in patients with asthma. Am J Respir Crit Care Med 1998; 157: 769-775. 